\title{
Karyopherin $\alpha 2$ induces apoptosis in tongue squamous cell carcinoma CAL-27 cells through the p53 pathway
}

\author{
LI GAO $^{1}$, LEI YU ${ }^{2}$, CHUN-MING LI $^{1}$, YING LI ${ }^{3}$, BAO-LIN JIA ${ }^{1}$ and BIN ZHANG ${ }^{3}$ \\ Departments of ${ }^{1}$ Oral and Maxillofacial Surgery, and ${ }^{2}$ General Surgery, The Second Affiliated Hospital of \\ Harbin Medical University; ${ }^{3}$ Institute of Hard Tissue Development and Regeneration, The Second Affiliated Hospital of \\ Harbin Medical University, Heilongjiang Academy of Medical Sciences, Harbin, Heilongjiang 150001, P.R. China
}

Received December 18, 2015; Accepted January 15, 2016

DOI: $10.3892 / o r .2016 .4750$

\begin{abstract}
Tumor onset and progression are associated with dysfunction of the nuclear transport machinery at the level of import and export receptors. However, the role of Karyopherin a2 (KPNA2) in human tongue squamous cell carcinoma (TSCC) remains unknown. We assessed the proliferation, apoptosis and migration of TSCC CAL-27 cells using wound healing, Transwell and MTT assays, western blotting, electron microscopy and acridine orange/ethidium bromide staining following knockdown of KPNA2. The results revealed the antiproliferative, proapoptotic and anti-migratory effects of KPNA2 silencing on the TSCC CAL-27 cells. Moreover, the knockdown of KPNA2 proved to be accompanied by the upregulation of active caspase-3, cytochrome $c$, Bax, Bad and decreased expression of Bcl-2, p-Bad and XIAP. KPNA2 activated the caspase-dependent pathway in the CAL-27 cells with upregulation of $\mathrm{p} 53, \mathrm{p} 21^{\mathrm{Cip} 1 / \text { Waf } 1}$ and $\mathrm{p} 16^{\mathrm{INK} 4 \mathrm{a}}$. Thus, the present study demonstrated that $\mathrm{p} 53 / \mathrm{p} 21^{\text {Cip1/Waf } 1 / \mathrm{p} 16^{\text {INK4a }} \text { may }}$ be an important pathway involved in the function of KPNA2 in TSCC CAL-27 cells.
\end{abstract}

\section{Introduction}

Tongue squamous cell carcinoma (TSCC) is one type of head and neck squamous cell carcinoma and remains one of the top 10 leading cancers in the US (1). Despite the largely improved surgical and medical management of patients with TSCC, recurrence of the carcinoma remains one of the crucial impediments in its treatment (2). The main reason for the high mortality rate is the lack of diagnostic methods for early stage detection and effective strategies for treatment. Therefore, understanding the molecular pathogenesis and uncovering

Correspondence to: Dr Bin Zhang, Institute of Hard Tissue Development and Regeneration, The Second Affiliated Hospital of Harbin Medical University, Heilongjiang Academy of Medical Sciences, Harbin, Heilongjiang 150001, P.R. China

E-mail: zhangbhyd@126.com

Key words: karyopherin $\alpha 2$, apoptosis, CAL-27 cells, tongue squamous cell carcinoma molecular biomarkers of TSCC would facilitate early detection and improve the survival of patients.

Karyopherin $\alpha 2$ (KPNA2), a member of the importin $\alpha$ family, is thought to play an important role in nucleocytoplasmic transport (3-5). Recently, clinical studies have demonstrated that KPNA2 is upregulated in multiple malignancies and is associated with an adverse outcome in affected patients (6-12). The biological functions of KPNA2 have been examined in various cancer cell lines; for example, overexpression of KPNA2 in a benign breast cell line increased cell colony formation ability and migration activity in a manner similar to that found in malignant cells (13). KPNA2 can also enhance cell migratory ability and viability (13). Additionally, knockdown of KPNA2 inhibited the proliferation of cells derived from prostate (12) and ovarian cancer (14). However, the role of KPNA2 in TSCC disease progression remains unclear. Although KPNA2 plays an important role in cancers, limited information is available regarding factors that control its expression. Therefore, the molecular mechanisms underlying knockdown of KPNA2 remain to be further elucidated.

In the present study, we reported that KPNA2 knockdown inhibited the growth and migration, and induced apoptosis of TSCC, and the molecular mechanisms were found to be associated with the enhancement of intracellular caspase- 3 and activation of the p53 signaling pathway. In brief, the results of our study may provide greater insight into improving the therapeutic efficacy of TSCC.

\section{Materials and methods}

Reagents. Antibodies for Bax and Bcl-2 were obtained from Sangong Biotech (Shanghai, China). KPNA2, Bad, p-Bad, cytochrome $c$ and p53 were purchased from Cell Signaling Technology (Danvers, MA, USA), p21 Cip1/Waf1 was purchased from BD Pharmingen (Franklin Lakes, NJ, USA), and p16 $6^{\mathrm{INK} 4 \mathrm{a}}$ was obtained from Santa Cruz Biotechnology (Santa Cruz, CA, USA). Other chemicals were purchased from Sigma-Aldrich (St. Louis, MO, USA).

CAL-27 cell culture. The TSCC CAL-27 cell line was provided by the Department of Oral and Maxillofacial Surgery, The Second Affiliated Hospital of Harbin Medical University (Heilongjiang, China), and cultured in RPMI-1640 medium 
containing $10 \%(\mathrm{v} / \mathrm{v})$ heat-inactivated fetal bovine serum (FBS; Gibco, Grand Island, NY, USA) at $37^{\circ} \mathrm{C}$ in an incubator containing humidified air with $5 \%(\mathrm{v} / \mathrm{v}) \mathrm{CO}_{2}$.

RNA interference. The cells were transfected using the Lipofectamine 2000 reagent (Life Technologies, Carlsbad, CA, USA) according to the manufacturer's instructions. A pool of two sequence-validated and knockdown-warranted KPNA2-siRNA were used: homo-1111, 5'-GACUCAGGUUG UGAUUGAUTT-3' and 5'-AUCAAUCACAACCUGAGUC TT-3'; homo-1400, 5'-CCGUUGAUGAACCUCUUAATT-3' and 5'-UUAAGAGGUUCAUCAACGGTT-3' (GenePharma, Shanghai, China). Commercial FAM-tagged, negative control siRNAs (NC siRNAs), 5'-UCCUCCGAACGUGUCACG UTT-3' and 5'-ACGUGACACGUUCGGAGAATT-3' (GenePharma) were used as an efficiency control and as a control for unspecific side-effects. Cell lysates were prepared for western blotting $48 \mathrm{~h}$ after transfection to determine the efficiency of gene expression ablation.

MTT cell proliferation and viability assay. An MTT assay was carried out to evaluate the cell viability as previously described (15). Cells $\left(8 \times 10^{3}\right)$ were seeded onto 96-well plates $24 \mathrm{~h}$ before treatment with KPNA2-siRNA for $48 \mathrm{~h}$ using Lipofectamine 2000. After $48 \mathrm{~h}, 15 \mu \mathrm{l}(5 \mathrm{mg} / \mathrm{ml})$ MTT (Sigma-Aldrich) was added to each well, and the cells were incubated for a further $4 \mathrm{~h}$ at $37^{\circ} \mathrm{C}$. After incubation, $150 \mu \mathrm{l}$ dimethyl sulfoxide (DMSO) was added to dissolve the crystals. The mixtures were shaken for 10-15 min to fully dissolve the crystals. Absobance (A570) was measured using a Tecan microplate reader, and cell viability was calculated as the percentage change in A570 between the control and treated cells.

Acridine orange/ethidium bromide fluorescence staining. The cells were incubated with acridine orange and ethidium bromide (AO/EB) mixing solution for 5 min (Solarbio of Biotechnology, Beijing, China; http://solarbio.en.alibaba. com) (16). Cellular morphological changes were examined using fluorescence microscopy (3200) at a magnification of $\mathrm{x} 200$. The percentage of apoptotic cells was calculated by the following formula: Apoptotic rate $(\%)=$ number of apoptotic cells/number of all cells counted $(17,18)$.

Western blot analysis. Total protein was extracted from the CAL-27 cells for immunoblotting analysis. Protein samples ( $80 \mu \mathrm{g}$ of protein) were separated with $12 \%$ sodium dodecyl sulfate-polyacrylamide gel electrophoresis (SDS-PAGE) and blotted to nitrocellulose membranes. After blocking, the membranes were probed with Bcl-2 (1:1,000 dilution), Bax (1:1,000 dilution), Bad (1:500 dilution), p-Bad (1:500 dilution), cytochrome $c$ (1:500 dilution), KPNA2 (1:1,000 dilution), XIAP

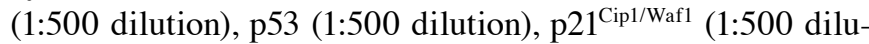
tion), p16 ${ }^{\text {INK4a }}$ (1:200 dilution) and glyceraldehyde-3-phosphate dehydrogenase (GAPDH; 1:1,000 dilution) antibodies incubated overnight at $4^{\circ} \mathrm{C}$. Infrared (IR) fluorescent dye-labeled secondary antibody (Alexa Fluor; Molecular Probes, Eugene, OR, USA; http://probes.invitrogen.com) was incubated with the membrane for $1 \mathrm{~h}$. Western blotting bands were collected using an IR Imaging System (LI-COR Biosciences, Lincoln,
NE, USA; http://www. licor.com), and the band density was quantified using Odyssey 3.0 software for each group and normalized to GAPDH.

Caspase-3 activity assay. A total of $5 \times 10^{3}$ cells were seeded in 96-well cell culture plates. After a $48 \mathrm{~h}$ siRNA treatment, apoptosis rates were measured based on the activation of caspase-3 effectors using the caspase-3 activity assay kit (Beyotime, China) according to the manufacturer's instructions. All samples were performed in triplicate.

Wound healing assay. CAL-27 cells were cultured in a 6-well plate for $24 \mathrm{~h}$. Wound healing assay was carried out by introducing a small linear scratch with a pipette tip. Then, the cells in the each well were exposed to serum-free Dulbecco's modified Eagle's medium (DMEM) containing the indicated concentrations of KPNA2-siRNA for $48 \mathrm{~h}$. The intervals after the scratch in the cultured cells were photographed under a phase-contrast microscope (magnification, x200) to monitor the cell migration ability.

Transwell assay. Transwell assay was performed using a Transwell chamber with pore size of $8.0 \mu \mathrm{m}$ (Millipore, Billerica, MA, USA). The cells were resuspended in serum-free medium, and then planted into the upper chamber with 5\% $\mathrm{CO}_{2}$ at $37^{\circ} \mathrm{C}$. After treatment with KPNA2-siRNA for $48 \mathrm{~h}$, the cells in the upper chamber were removed, and the attached cells in the lower section were stained with $0.1 \%$ crystal violet. The migration rate was quantified by counting the migrating cells in 6 random fields under a light microscope.

Data analysis. Data were obtained from 3 to 6 independent experiments and are presented as the mean \pm standard deviation. Data were evaluated by the unpaired Student's t-test, and $\mathrm{P}<0.05$ was considered to represent a significant difference.

\section{Results}

KPNA2 knockdown suppresses the viability of CAL-27 cells. Successful transfection of KPNA2-siRNA was verified by our data shown in Fig. 1A and B. Western blotting showed that the KPNA2 protein level was decreased (Fig. 1A and B). Fig. 1C shows that the viability of the CAL-27 cells transfected with KPNA2-siRNA was reduced by $58.1 \pm 6.8 \%$.

KPNA2 knockdown induces the apoptosis of CAL-27 cells. To assess whether increased apoptosis was involved in the significant decrease in cell viability following KPNA2 knockdown, AO/EB staining and electron microscopy were used to detect apoptotic cells. The results from our fluorescence microscopic analysis are shown in Fig. 2A. Three types of cells were recognized under a fluorescence microscope: live cells (green), apoptotic cells (yellow) and necrotic cells (red). Forced expression following KPNA2 knockdown induced substantial apoptotic cells $(\mathrm{P}<0.05)$, while the empty vector failed to do so. Under an electron microscope, the cells with KPNA2 knockdown exhibited robust changes in microstructure, including cell surface microvilli reduction, nuclear chromatin condensation, margination and membrane blistering (Fig. 2B). 
A

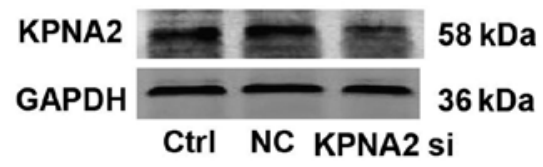

B

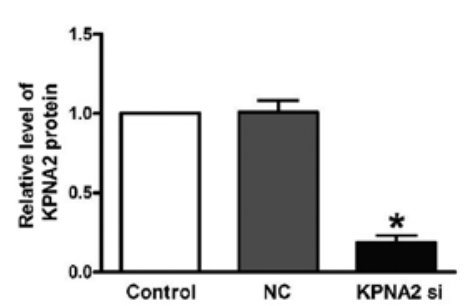

C

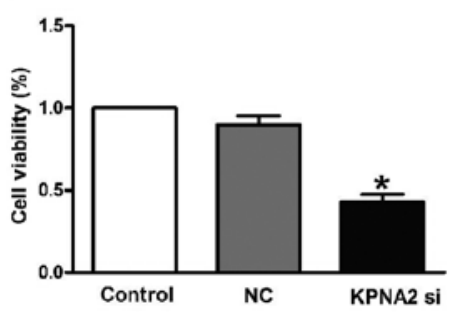

Figure 1. KPNA2 knockdown inhibits the survival of CAL-27 cells. Cal-27 cells were transfected with KPNA2-directed siRNA. NC (negative control) represents empty vectors $(1 \mu \mathrm{g} / \mathrm{ml}$ of pc-DNA3.1 plasmid) transfected into CAL-27 cells. (A) KPNA2 expression was determined by western blot analysis. (B) Average band density from three independent experiments. (C) Relative cell viability determined by the MTT assay. " $\mathrm{P}<0.05$ compared with the control, $\mathrm{n}=6$ independent experiments for each condition.

A
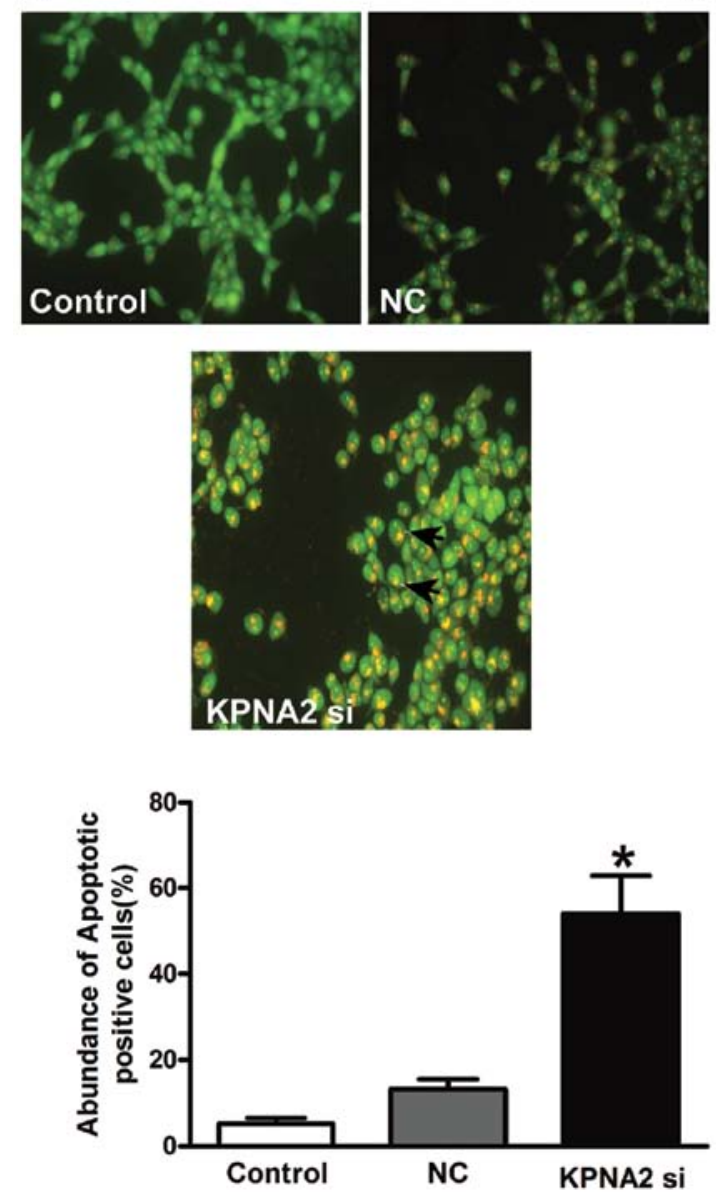

B
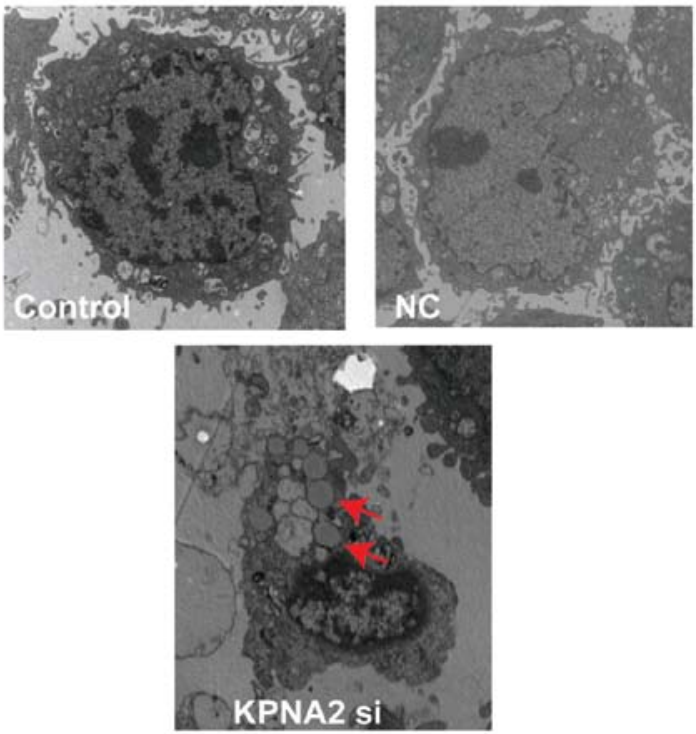

Figure 2. (A) KPNA2 knockdown induces apoptosis in CAL-27 cells. Acridine orange/ethidium bromide (AO/EB) staining to detect changes in the nucleus. Red arrows indicate apoptotic cells. (B) Micromorphological changes in cellular organelles examined by transmission electron microscopy. Scale bars, $2 \mathrm{~mm}$. Statistical bar graph of apoptotic cells by AO/EB staining. Arrows indicate apoptotic cells. The data are expressed as means $\pm S E M, n=3$ for each group; ${ }^{*} \mathrm{P}<0.05$ vs. control.
KPNA2 knockdown inhibits the migration of CAL-27 cells. In addition to cellular proliferation, we also examined the effect of KPNA2 on the migration activity of CAL-27 cells. The wound healing assay in vitro was carried out to determine the cell migration ability of the CAL-27 cells in the absence and presence of KPNA2 knockdown. Fig. 3A shows the quantified wound closure in the CAL-27 cells after KPNA2-siRNA treatment. Wound closure was reduced in the KPNA2-siRNAtreated CAL-27 cells at $48 \mathrm{~h}$ after wounding, compared with the rate of closure of the control group. Moreover, Transwell migration assay was also performed in the CAL-27 cells after KPNA2-siRNA treatment. In agreement with the wound healing assay, treatment with KPNA2-siRNA produced a reduction in the number of migrated cells (Fig. 3B). These data demonstrated that KPNA2 induced the suppression of migration of the CAL-27 cells.

KPNA2 knockdown activates caspase-dependent proapoptotic signaling pathways. To explore the mechanisms by which KPNA2 knockdown induces apoptosis in CAL-27 cells, we measured the downstream proteins of the KPNA2 apoptotic pathway, including Bax, Bcl-2, Bad, p-Bad cytochrome $c$ and XIAP. Silencing of KPNA2 upregulated Bad, cytochrome $c$ and Bax, and downregulated p-Bad and Bcl-2 expression (Fig. 4A, B and D). Knockdown of KPNA2 decreased XIAP protein expression, which acts as a vital anti-apoptotic protein (Fig. 4E), 
A

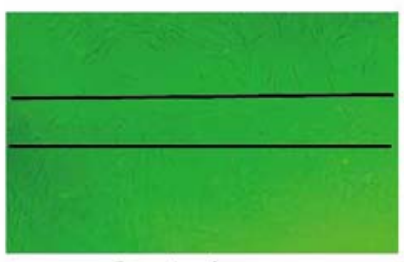

Control

B

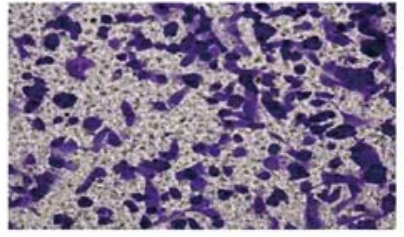

Control

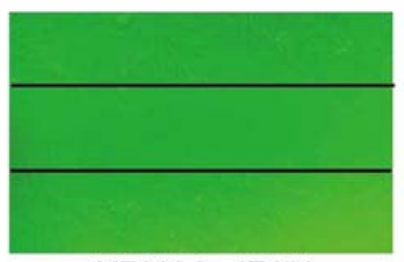

KPNA2-siRNA

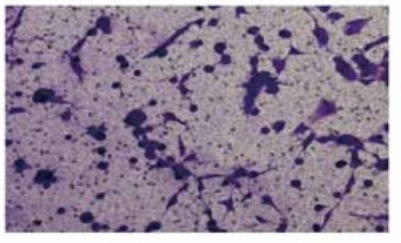

KPNA2-siRNA
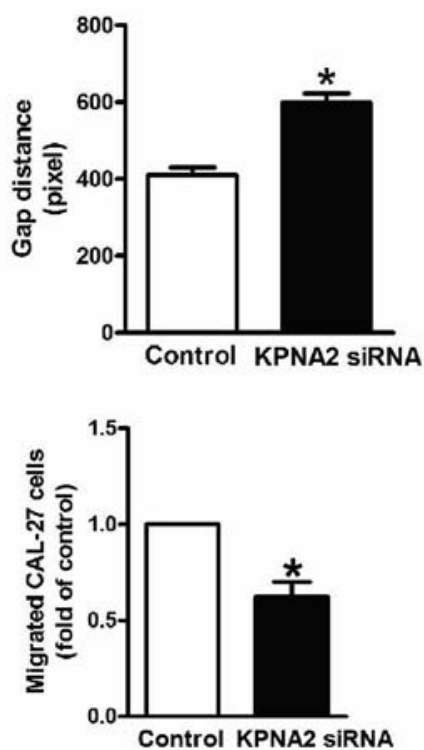

Figure 3. Effect of KPNA2 siRNA on the proliferation and migration of CAL-27 cells. (A) KPNA2 siRNA inhibited the proliferation of CAL-27 cells by wound healing assay. (B) Transwell assay indicated that the migration of CAL-27 cells was obviously inhibited by KPNA2 siRNA; "P $<0.05$ vs. control.

A

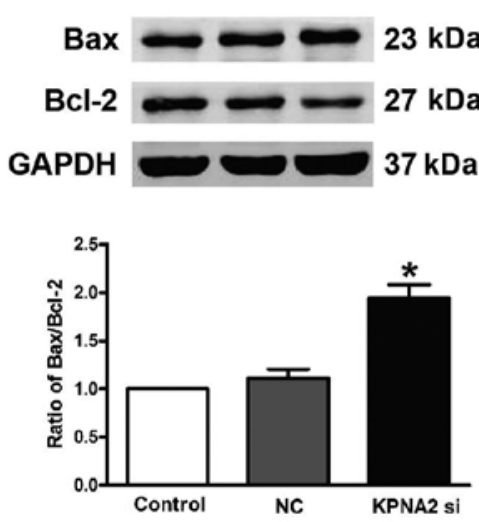

D
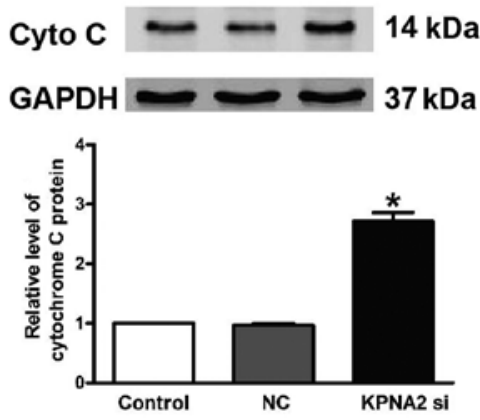

B

C
$\mathrm{Bad}=23 \mathrm{kDa}$

p-Bad - - $23 \mathrm{kDa}$
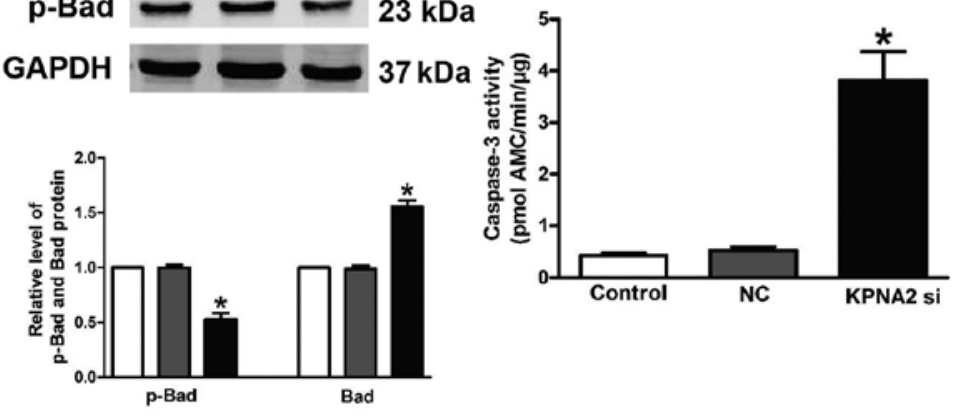

E
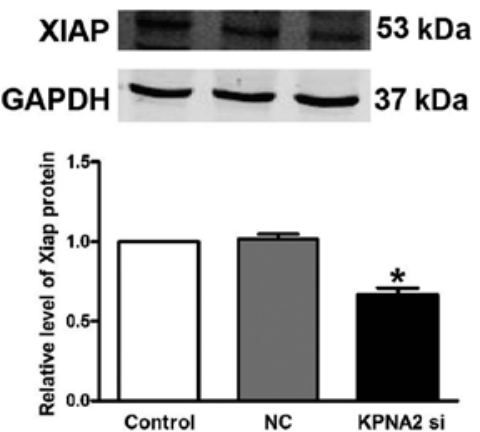

Figure 4. KPNA2 knockdown alters p-Bad, Bad, Bax, Bcl-2 cytochrome $c$ and XIAP expression, and promotes caspase-3 activation. Western blotting was used to detect (A) Bax, Bcl-2, (B) p-Bad, Bad, (D) cytochrome $c$ and (E) XIAP expression in the CAL-27 cells transfected with KPNA2. Relative expression of Bax, Bcl-2, p-Bad, Bad and XIAP was normalized to GAPDH. n=3 independent experiments for each group. (C) Activation of caspase-3 by KPNA2-directed siRNA. The data are expressed as mean \pm SEM, similar results were observed from another three experiments; ${ }^{*} \mathrm{P}<0.05$ compared with the control.

while the empty vector did not affect the above proteins. In addition, relative caspase-3 activity was significantly increased by 2.2-fold due to KPNA2-siRNA transfection, but no obvious change was noted with the NC (Fig. 4C).
Knockdown of KPNA2 decreases expression of p53, p2 $1^{\text {Cipl/Wafl }}$ and p16 $6^{\text {INKAa }}$ in $C A L-27$ cells. To further explore the mechanisms associated with KPNA2 knockdown, the expression of $\mathrm{p} 53, \mathrm{p} 21^{\mathrm{Cip} / \mathrm{Waf} 1}$ and $\mathrm{p} 16^{\mathrm{INK} 4 \mathrm{a}}$ at the protein level 
A
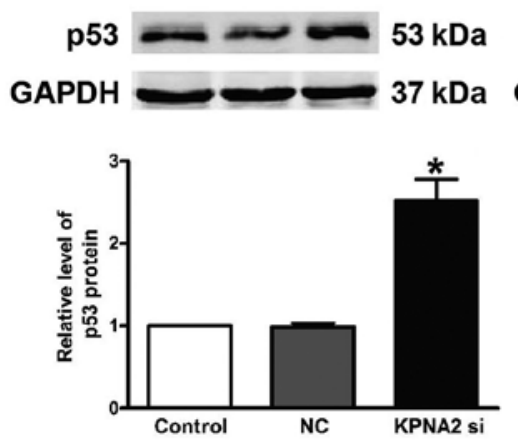

B

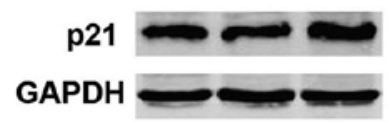

$21 \mathrm{kDa}$

$37 \mathrm{kDa}$

C

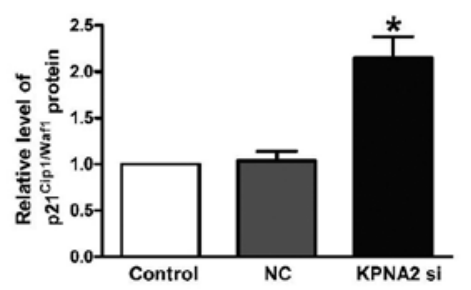

Figure 5. KPNA2 knockdown induces the expression of p53, p21 ${ }^{\text {Cip1/Waf1 }}$ and p16 ${ }^{\mathrm{INK} 4 \mathrm{a}}$ in CAL-27 cells. (A) p53, (B) p21 Cip1/Waf1 and (C) p16 $6^{\mathrm{INK} 4 \mathrm{a}}$ protein levels. The data are expressed as mean $\pm \mathrm{SEM}, \mathrm{n}=3$ for each group. ${ }^{*} \mathrm{P}<0.05$ compared with the control. GAPDH, glyceraldehyde-3-phosphate dehydrogenase; KD, kilodalton.

was demonstrated to be markedly upregulated in the CAL-27 cells. Knockdown of KPNA2 caused an aberrant upregulation of p53 (Fig. 5A), p21 $1^{\mathrm{Cip} 1 / \text { Waf1 }}$ (Fig. 5B) and p16 ${ }^{\mathrm{INK} 4 \mathrm{a}}$ (Fig. 5C). These observations showed that $\mathrm{p} 53 / \mathrm{p} 21^{\mathrm{Cip} 1 / \text { Waf } 1 / \mathrm{p} 16^{\mathrm{INK} 4 \mathrm{a}} \text { has an }}$ important role in KPNA2-induced apoptosis in CAL-27 cells.

\section{Discussion}

In the present study, we suggest that knockdown of KPNA2 has a potent antiproliferative effect on CAL-27 cells by inducing apoptosis in vitro. We further elucidated that activation of both caspase-3-dependent and p53-dependent pathways are important mechanisms associated with KPNA2-induced apoptosis. Therefore, the present study may provide a new pathway into the clinical role of KPNA2 in TSSC.

Previous studies have shown that KPNA2 takes part in anticancer activities (6-12,19-21) and its alteration is often associated with an adverse outcome for breast carcinomas (7-9), esophageal (10), lung (11), prostate (12), brain (21) and ovarian cancer $(19,20)$. However, the impact of KPNA2 on the growth and apoptosis of TSSC remains unknown.

The present study showed the antiproliferative, proapoptotic and anti-migratory effects of KPNA 2 on tongue squamous cell carcinoma (TSCC) cells. We found that KPNA2-siRNA significantly inhibited the growth of CAL-27 cells. AO/EB staining displayed the apoptotic nuclear changes in CAL-27 cells. These findings confirmed that the inhibition of KPNA2 was able to cause apoptosis of TSCC cells. We further tested whether the KPNA2-siRNA led to the inhibition of migration in CAL-27 cells. The results confirmed that KPNA2-knockdown was able to inhibit the migration of TSCC cells.

Then, several assays were carried out to understand the molecular mechanism underlying the antitumor effects of KPNA2 knockdown on TSCC. Several studies have reported that Bax, Bcl-2 and caspase-3 are the key molecules participating in the apoptosis in CAL-27 cells. Chloroform extracts of Solanum lyratum induced apoptosis by upregulating Bax protein expression and caspase-3 activity and downregulating Bcl-2 expression in CAL-27 cells (22). The AKT serine/threonine protein kinase modulates bufalin-triggered intrinsically induced apoptosis in CAL-27 cells by upregulating Bax and caspase-3 expression and downregulating Bcl-2 (23). The above results are consistent with our findings that KPNA2 induces apoptosis by regulating Bcl-2 and Bax, and activates caspase-3 expression in CAL-27 cells. We observed that the ratio of $\mathrm{Bcl}-2 / \mathrm{Bax}$ was significantly decreased, indicating that KPNA2 knockdown induced apoptosis in the CAL-27 cells. In addition, Bad, a member of the Bcl-2 family, normally binds to the Bcl-2/Bcl-X complex and triggers apoptosis (24). Bad was downregulated, while levels of p-Bad and XIAP were elevated following KPNA2 knockdown. XIAP interacts with caspase-3 to block its full activation, substrate cleavage and cell death (25). Furthermore, Bax and Bad activate caspase-3. These data confirm that caspase-3-dependent apoptotic signaling plays a critical role in the anticancer activity of KPNA2 knockdown.

The p53 signaling pathway is also pivotal in apoptosis $(26,27)$, such as the tissue dependent interactions between p53 and bcl-2 in vivo (28). Adenoviral-mediated p53 overexpression diversely influences the cell cycle of HepG2 and CAL-27 cell lines upon cisplatin and methotrexate treatment (29). An indirubin derivative, indirubin-3'-monoxime, induced apoptosis in oral cancer tumorigenesis through caspase- 3 activity and upregulation of p53 expression in CAL-27 cells (30). Our research showed that caspase-3 activity was increased after KPNA2 knockdown. We demonstrated that KPNA2 is able to induce apoptosis in CAL-27 cells, and this effect appears to

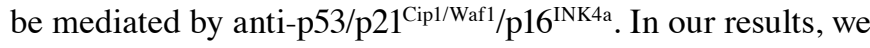
observed that the expression of p53 protein in CAL-27 cells was significantly higher than that noted in the control group $(\mathrm{P}<0.05)$, as was the expression of $\mathrm{p} 21^{\mathrm{Cip} 1 / \text { Waf1 }}$ and $\mathrm{p} 16^{\mathrm{INK} 4 \mathrm{a}}$ protein $(\mathrm{P}<0.05)$. We observed that KPNA2 resulted in the

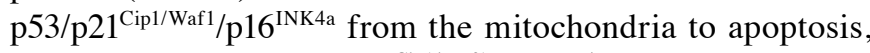

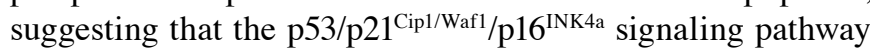
is involved in apoptosis induced by KPNA2.

In conclusion, the present study demonstrated that KPNA2 knockdown inhibited the proliferation and migration, and promoted the apoptosis of TSCC cells, which is associated with increased intracellular caspase-3 and activa-

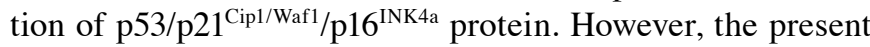
study does not rule out the potential participation of other factors/pathways as mechanisms for the KPNA2-knockdown apoptotic effects in CAL-27 cells. The present study suggests KPNA2 as a new therapeutic agent for TSCC. 


\section{References}

1. Siegel RL, Miller KD and Jemal A: Cancer statistics, 2015. CA Cancer J Clin 65: 5-29, 2015.

2. Song B, Yang Y, Wang YL, Fan XH, Huang YM, Ci HS and Zuo JH: Adenovirus expressing IFN- $\lambda$ (Ad/hIFN- $\lambda$ ) produced anti-tumor effects through inducing apoptosis in human tongue squamous cell carcinoma cell. Int J Clin Exp Med 8: 12509-12518, 2015 .

3. Tseng SF, Chang CY, Wu KJ and Teng SC: Importin KPNA2 is required for proper nuclear localization and multiple functions of NBS1. J Biol Chem 280: 39594-39600, 2005.

4. Zannini L, Lecis D, Lisanti S, Benetti R, Buscemi G, Schneider C and Delia D: Karyopherin-alpha2 protein interacts with Chk2 and contributes to its nuclear import. J Biol Chem 278: 42346-42351, 2003.

5. Teng SC, Wu KJ, Tseng SF, Wong CW and Kao L: Importin KPNA2, NBS1, DNA repair and tumorigenesis. J Mol Histol 37: 293-299, 2006

6. Dahl E, Kristiansen G, Gottlob K, Klaman I, Ebner E, Hinzmann B, Hermann K, Pilarsky C, Dürst M, KlinkhammerSchalke M, et al: Molecular profiling of laser-microdissected matched tumor and normal breast tissue identifies karyopherin alpha2 as a potential novel prognostic marker in breast cancer. Clin Cancer Res 12: 3950-3960, 2006.

7. Sotiriou C, Wirapati P, Loi S, Harris A, Fox S, Smeds J, Nordgren H, Farmer P, Praz V, Haibe-Kains B, et al: Gene expression profiling in breast cancer: Understanding the molecular basis of histologic grade to improve prognosis. J Natl Cancer Inst 98: 262-272, 2006.

8. Dankof A, Fritzsche FR, Dahl E, Pahl S, Wild P, Dietel M, Hartmann A and Kristiansen G: KPNA2 protein expression in invasive breast carcinoma and matched peritumoral ductal carcinoma in situ. Virchows Arch 451: 877-881, 2007.

9. Gluz O, Wild P, Meiler R, Diallo-Danebrock R, Ting E, Mohrmann S, Schuett G, Dahl E, Fuchs T, Herr A, et al: Nuclear karyopherin alpha2 expression predicts poor survival in patients with advanced breast cancer irrespective of treatment intensity. Int J Cancer 123: 1433-1438, 2008.

10. Sakai M, Sohda M, Miyazaki T, Suzuki S, Sano A, Tanaka N, Inose T, Nakajima M, Kato $\mathrm{H}$ and Kuwano H: Significance of karyopherin- $\alpha 2$ (KPNA2) expression in esophageal squamous cell carcinoma. Anticancer Res 30: 851-856, 2010.

11. Wang CI, Wang CL, Wang CW, Chen CD, Wu CC, Liang Y, Tsai YH, Chang YS, Yu JS and Yu CJ: Importin subunit alpha-2 is identified as a potential biomarker for non-small cell lung cancer by integration of the cancer cell secretome and tissue transcriptome. Int J Cancer 128: 2364-2372, 2011.

12. Mortezavi A, Hermanns T, Seifert HH, Baumgartner MK, Provenzano M, Sulser T, Burger M, Montani M, Ikenberg K, Hofstädter F, et al: KPNA2 expression is an independent adverse predictor of biochemical recurrence after radical prostatectomy. Clin Cancer Res 17: 1111-1121, 2011.

13. Noetzel E, Rose M, Bornemann J, Gajewski M, Knüchel R and Dahl E: Nuclear transport receptor karyopherin- $\alpha 2$ promotes malignant breast cancer phenotypes in vitro. Oncogene 31: 2101-2114, 2012

14. Huang L, Wang HY, Li JD, Wang JH, Zhou Y, Luo RZ, Yun JP, Zhang Y, Jia WH and Zheng M: KPNA2 promotes cell proliferation and tumorigenicity in epithelial ovarian carcinoma through upregulation of c-Myc and downregulation of FOXO3a. Cell Death Dis 4: e745, 2013.

15. Khan M, Yu B, Rasul A, Al Shawi A, Yi F, Yang H and Ma T: Jaceosidin induces apoptosis in U87 glioblastoma cells through G2/M phase arrest. Evid Based Complement Alternat Med 2012: $703034,2012$.
16. McGahon AJ, Martin SJ, Bissonnette RP, Mahboubi A, Shi Y, Mogil RJ, Nishioka WK and Green DR: The end of the (cell) line: Methods for the study of apoptosis in vitro. Methods Cell Biol 46: 153-185, 1995.

17. Ni B, Bai FF, Wei Y, Liu MJ, Feng ZX, Xiong QY, Hua LZ and Shao GQ: Apoptosis induced by lipid-associated membrane proteins from Mycoplasma hyopneumoniae in a porcine lung epithelial cell line with the involvement of caspase 3 and the MAPK pathway. Genet Mol Res 14: 11429-11443, 2015.

18. He Y, Chen W, Hu Y, Luo B, Wu L, Qiao Y, Mo Q, Xu R, Zhou Y, Ren Z, et al: E. adenophorum induces cell cycle and apoptosis of renal cells through mitochondrial pathway and caspase activation in Saanen goat. PLoS One 10: e0138504, 2015.

19. Zheng M, Tang L, Huang L, Ding H, Liao WT, Zeng MS and Wang HY: Overexpression of karyopherin-2 in epithelial ovarian cancer and correlation with poor prognosis. Obstet Gynecol 116: 884-891, 2010.

20. He L, Ding H, Wang JH, Zhou Y, Li L, Yu YH, Huang L, Jia WH, Zeng M, Yun JP, et al: Overexpression of karyopherin 2 in human ovarian malignant germ cell tumor correlates with poor prognosis. PLoS One 7: e42992, 2012.

21. Gousias K, Becker AJ, Simon M and Niehusmann P: Nuclear karyopherin a2: A novel biomarker for infiltrative astrocytomas. J Neurooncol 109: 545-553, 2012

22. Chiu CH, Chou YC, Lin JP, Kuo CL, Lu HF, Huang YP, Yu CC, Lin ML and Chung JG: Chloroform extract of Solanum lyratum induced G0/G1 arrest via p21/p16 and induced apoptosis via reactive oxygen species, caspases and mitochondrial pathways in human oral cancer cell lines. Am J Chin Med 43: 1453-1469, 2015.

23. Tsai SC, Lu CC, Lee CY, Lin YC, Chung JG, Kuo SC, Amagaya S, Chen FN, Chen MY, Chan SF, et al: AKT serine/threonine protein kinase modulates bufalin-triggered intrinsic pathway of apoptosis in CAL 27 human oral cancer cells. Int J Oncol 41: 1683-1692, 2012

24. Huang $\mathrm{C}, \mathrm{Gu} \mathrm{H}$, Zhang $\mathrm{W}$, Herrmann JL and Wang $\mathrm{M}$ : Testosterone-down-regulated Akt pathway during cardiac ischemia/reperfusion: A mechanism involving BAD, Bcl-2 and FOXO3a. J Surg Res 164: e1-e11, 2010.

25. Paulsen M, Ussat S, Jakob M, Scherer G, Lepenies I, Schütze S, Kabelitz D and Adam-Klages S: Interaction with XIAP prevents full caspase-3/-7 activation in proliferating human $\mathrm{T}$ lymphocytes. Eur J Immunol 38: 1979-1987, 2008.

26. Aroui S, Dardevet L, Ajmia WB, de Boisvilliers M, Perrin F, Laajimi A, Boumendjel A, Kenani A, Muller JM and De Waard M: A novel platinum-maurocalcine conjugate induces apoptosis of human glioblastoma cells by acting through the ROS-ERK/AKT-p53 pathway. Mol Pharm 12: 4336-4348, 2015.

27. Ikenberg K, Valtcheva N, Brandt S, Zhong Q, Wong CE, Noske A, Rechsteiner M, Rueschoff JH, Caduff R, Dellas A, et al: KPNA2 is overexpressed in human and mouse endometrial cancers and promotes cellular proliferation. J Pathol 234: 239-252, 2014.

28. Li X, Miao X, Wang H, Xu Z and Li B: The tissue dependent interactions between $\mathrm{p} 53$ and $\mathrm{Bcl}-2$ in vivo. Oncotarget 6: 35699-35709, 2015.

29. Kraljević Pavelić S, Marjanović M, Poznić M and Kralj M: Adenovirally mediated p53 overexpression diversely influence the cell cycle of HEp-2 and CAL 27 cell lines upon cisplatin and methotrexate treatment. J Cancer Res Clin Oncol 135: 1747-1761, 2009.

30. Lo WY and Chang NW: An indirubin derivative, indirubin3'-monoxime suppresses oral cancer tumorigenesis through the downregulation of survivin. PLoS One 8: e70198, 2013. 